\title{
PECADOS CAPITALES DE LA NOVELA ${ }^{1}$
}

\author{
Miguel Ángel MÁRQUEZ \\ Universidad de Huelva \\ marquez@uhu.es
}

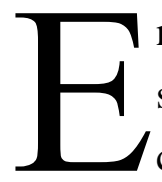
n «La desprestigiada herencia de Cervantes», M. Kundera se adhirió a las tesis de Husserl sobre la crisis de la cultura en Europa, que se iniciaría, según ambos, en la Edad Moderna como consecuencia del desarrollo de las ciencias particulares, lo que «llevó al hombre hacia los túneles de las disciplinas especializadas» (Kundera, 2007: 14). Desde entonces, y a medida que progresaba el conocimiento científico-técnico, la filosofía y las ciencias habrían abandonado el estudio holístico del hombre y de su vida. Sin embargo, Kundera señala que las obras de Cervantes y Rabelais también son productos de la Edad Moderna, y con ellas, la novela habría asumido la indagación de ese «ser olvidado» (Kundera, 2007: 15). Así, las grandes novelas modernas y contemporáneas (El Quijote, La Comedia humana, Madame Bovary, Moby Dick, Ulises, etc.) ofrecerían a sus lectores la exploración de un «territorio humano» hasta ese momento desconocido, como había hecho la filosofía en los siglos precedentes.

En paralelo a este logro cognitivo, puede observarse un largo proceso histórico en el que la novela ha desplazado del centro del canon a los otros géneros. Este fenómeno resulta novedoso, porque las novelas antigua y medieval nunca gozaron de parecida estima pública. En realidad, se consideraban géneros menores, lectura más para el delectare que el prodesse $e^{2}$ A lo largo de estos cuatro últimos siglos, el género novelístico ha incorporado los elementos que facilitaban su canonización, los factores que elevaban su estilo hasta la sublimidad que corresponde a los géneros mayores. ¿Cuáles son estos elementos según Bloom? «Uno solo irrumpe en el canon por fuerza estética, que se compone primordialmente de la siguiente amalgama: dominio del lenguaje metafórico, originalidad, poder cognitivo, sabiduría y exuberancia en la dicción»(Bloom, 2001: 39).

Esos cinco componentes de Bloom se inspiran directa y llamativamente en los factores de sublimidad enunciados por el autor anónimo del tratado Sobre lo sublime, casi dos mil años antes:

\footnotetext{
${ }^{1}$ Después de veinte años de amistad, en los que hemos compartido congresos de teoría de la literatura, seminarios de métrica, tesis doctorales y algún concurso de méritos — no siempre en el mismo lado de la mesa—, son muchos los motivos de gratitud que he acumulado con José Enrique Martínez. Enumerarlos hoy solo sería la pueril y prolija tentativa de saldarlos con palabras.

${ }^{2}$ A pesar de novelas como el Tristán e Isolda de Gottfried de Estrasburgo, o la imagen que podemos hacernos del Satiricón de Petronio. Cf. García Gual (2008).
} 
Son, pues, cinco las fuentes, como uno las podría llamar, más productivas de la grandeza de estilo. [...]. La primera y más importante es el talento para concebir grandes pensamientos [...]. La segunda es la pasión vehemente y entusiasta. Pero estos dos elementos de lo sublime son, en la mayoría de los casos, disposiciones innatas; las restantes, por el contrario, son productos de un arte: cierta clase de formación de figuras (éstas son de dos clases, figuras de pensamiento y figuras de dicción), y, junto a éstas, la noble expresión, a la que pertenecen la elección de palabras y la dicción metafórica y artística. La quinta causa de la grandeza de estilo y que encierra todas las anteriores, es la composición digna y elevada (De sublime 8.1).

La novela actual se aleja de esa trayectoria histórica que se inició con Cervantes, de su exigencia moral de conocimiento (Kundera, 2007), al mismo tiempo que desecha (¿voluntariamente?) los rasgos de la literatura canónica señalados tanto por el primer crítico de la tradición occidental (el PseudoLongino), como el crítico encargado de entonar «la elegía al canon». La decadencia del arte de la prosa, la banalidad, la ausencia de ironía, la pobreza metafórica, los caminos trillados son los pecados capitales que debemos censurar a la novela de los últimos decenios, y no solo a la novela de consumo.

\section{Descomposición}

En la historia de la literatura europea, nunca han faltado novelistas que perpetraran - como diría Borges - un estilo descompuesto, pero su abundancia hoy es aterradora, y no solo entre los autores de best-sellers, sino también entre quienes reciben lisonjas de la crítica y prestigiosos premios.

Aunque se tenía conciencia desde tiempos de Tucídides ${ }^{3}$, fue Dionisio de Halicarnaso el primero que sistematizó los conocimiento antiguos sobre la composición literaria, una teoría del arte de la prosa que comprende la melodía, la eufonía y el ritmo. Hoy casi nadie conoce esa teoría. Muchos novelistas profesionales ni siquiera parecen comprender la naturaleza de la prosa, que se compone siempre de miembros (cola) y se organiza alternando el estilo simple y el estilo periódico ${ }^{4}$. La consecuencia de esta ignorancia, o de este descuido, es una prosa mal compuesta, es decir, una prosa que no suena bien. Sin embargo, no ha pasado tanto tiempo desde que Amado Alonso (1986) analizó la prosa de ValleInclán con su particular teoría del período.

Anochecía cuando la silla de posta traspuso la Puerta Salaria y comenzamos a cruzar la campiña llena de misterio y de rumores lejanos. Era la campiña clásica de las vides y de los olivos, con sus acueductos ruinosos, y sus colinas que tienen la graciosa ondulación de los senos femeninos. La silla de posta caminaba por una vieja calzada: Las mulas del tiro sacudían pesadamente las colleras, y el golpe alegre y desigual de los cascabeles despertaba un eco en los floridos olivares (Valle-Inclán, 2007: 15).

Este es el principio de la «Sonata de Primavera». Al margen de la pátina del tiempo y de los gustos personales, nadie podrá recriminar a Valle-Inclán una prosa descompuesta. Tampoco a Borges.

\footnotetext{
${ }^{3}$ Tucídides dice de su obra: «Se trata de un logro para siempre más que de una obra de concurso para una audición de un momento» (Historia de la guerra del Peloponeso I, 22).

4 «Pero la prosa tiene toda la libertad y licencia para diversificar con variaciones la composición como quiera. El mejor estilo de todos es el que tenga el mayor número de pausas y variaciones de composición. Cuando se diga una cosa en estilo periódico, otra, sin período; cuando un período se componga de más cola, otro, de menos; cuando un colon sea más corto, otro, más largo; cuando uno sea más rápido, otro, más lento; y los ritmos sean cada vez distintos y haya toda clase de figuras, los tonos de voz (los llamados acentos) sean diferentes y oculten el hartazgo con la diversificación» (Dionisio de Halicarnaso, Sobre la composición literaria 19.9-11).
} 

Miguel Ángel Márquez

La obra visible que ha dejado este novelista es de fácil y breve enumeración. Son, por lo tanto, imperdonables las omisiones y adiciones perpetradas por madame Henri Bachelier en un catálogo falaz que cierto diario cuya tendencia protestante no es un secreto ha tenido la desconsideración de inferir a sus deplorables lectores - si bien éstos son pocos y calvinistas, cuando no masones y circuncisos. Los amigos auténticos de Menard han visto con alarma ese catálogo y aun con cierta tristeza. Diríase que ayer nos reunimos ante el mármol final y entre los cipreses infaustos y ya el Error trata de empañar su Memoria... Decididamente, una breve rectificación es inevitable (Borges, 2011: 108).

Por el contrario, la prosa que no respeta las reglas de la composición suena mal. Quizá el defecto menos disimulable sea la asonancia, que se produce cuando dos o más miembros consecutivos terminan con las mismas vocales tras el último acento ${ }^{5}$. En algunas ocasiones, el homeoteleuton puede ser un recurso voluntario con una función específica ${ }^{6}$, pero la mayoría de las veces la asonancia es un defecto que revela que el autor no tiene conciencia de los límites entre los miembros del período.

¿Te das cuenta, Gal, del día que elegiste para morir? Conociéndote, dudo mucho que sea casualidad. Es el tipo de bromas que te gustaba gastar, convencido como estabas de que nadie se iba a dar cuenta, pero a mí no me la juegas. [...]. Tú, que tanto hablabas de la muerte, que tanto escribías sobre ella, por fin estás también del otro lado. Nunca había perdido a nadie tan cercano. Par mí es algo nuevo no lo acabo de entender. Solías decir que los muertos no se van del todo, que de alguna manera siguen estando entre nosotros. Para la única verdad es que no estás. Te has ido para siempre Gal, lo demás no cuenta. Ya lo sé. Te conozco demasiado bien [...] $(\text { Lago, 2006, 14) })^{7}$.

Podríamos citar más ejemplos sacados de las primeras páginas de esta novela, ganadora del premio Nadal, y todavía muchos más recurriendo a otros novelistas actuales que cometen abundantes asonancias, pero no parece necesario. A un lector avisado le basta ojear las novedades en cualquier librería para cazar centenares de ellas al vuelo, como hacía Flaubert gritando en la «avenida del vocerío» las frases que acababa de escribir.

\section{Banalidad}

En la última novela de Saul Bellow (Ravelstein, 2000), el protagonista, Abe Ravelstein, brillante y excéntrico profesor de Filosofía Política en una universidad del Midwest, se hace millonario con las «superventas» de su último libro, a pesar de que en él expresa sus verdaderas opiniones y pensamientos. Los genios tutelares del personaje Ravelstein son Tucídides, Platón, Maquiavelo. Los genios tutelares de Bellow en esta novela son esos mismos autores, y El Banquete y La guerra del Peloponeso su horizonte referencial.

La apreciación que hacía Ravelstein de la gente que trataba a diario tenía este antecedente de amor inmenso o rabia incontenible. Él me recordaría que la 'cólera' estaba en la primera línea de la Ilíada: menin Achileos. Aquí es donde ve uno las principales vigas que sustentan la profunda sinceridad de las creencias de Ravelstein. Los héroes más grandes de todos, los filósofos, habían sido y serían siempre ateos. Después de los filósofos, en la procesión de Ravelstein, venía los poetas y estadistas. Tremendos historiadores como Tucídides. [...]. Ravelstein valoraba la Antigüedad clásica. Prefería Atenas, pero tenía un gran respeto por Jerusalén (Bellow, 2006: 65)

\footnotetext{
${ }^{5}$ Es decir, que riman en asonante.

${ }^{6}$ Por ejemplo, establecer vínculos metafóricos entre las palabras que asuenan, como a veces ocurre en la prosa de García Márquez.

${ }^{7}$ El énfasis con cursiva es mío.
} 
El Pseudo-Longino (Sobre lo sublime), aconseja al escritor joven que se imagine que Homero, Tucídides y Platón leerán su obra (De sublime 14):

También es bueno que nosotros, cuando estemos trabajando en un pasaje que exija sublimidad en la expresión y grandeza en los pensamientos, nos representemos en nuestras almas, si fuera necesario, cómo hubiera dicho eso mismo Homero, cómo lo hubieran hecho sublime Platón o Demóstenes o en su historia Tucídides. Pues, al presentarse ante nosotros como objetos de emulación aquellos grandes personajes y al aparecer ante nuestros ojos de forma sobresaliente, elevarán nuestras almas hacia las medidas ideales de perfección, que hemos imaginado. Y, aún más, si damos a nuestra imaginación esta sugerencia: ¿Cómo habrían escuchado este pasaje mío Homero y Demóstenes si hubieran estado presente? ¿Cuál habría sido su actitud ante él? supone un gran esfuerzo, en realidad, imaginar tal tribunal y una audiencia tal de nuestras propias palabras, y el pensar que tenemos que rendir cuentas ante tales héroes como jueces y testigos de nuestros escritos. Un estímulo más poderoso aún sería añadir: si yo escribo, ¿cómo lo recibirá la posteridad? Si un autor desde un principio teme decir algo que dure más allá de su propia vida y época, entonces, las cosas producidas por un espíritu tal serán necesariamente imperfectas y ciegas como abortos, pues no serán capaces de llegar a la perfección para asegurarse renombre en la posteridad.

Durante siglos, los escritores occidentales han seguido el consejo del Pseudo-Longino, al parecer hasta Bellow al principio del tercer milenio. Quizá por esta razón sus obras son profundas y difíciles ${ }^{8}$. Pero el auge de la «cultura popular» en el siglo XX ha terminado por desplazar la cultura, la verdadera y única cultura, arrinconándola como «alta cultura». De esta manera, la sección correspondiente en todos los periódicos mezcla la moda y el diseño, la música pop y la gastronomía, el cine comercial y los bestsellers. La banalidad no es la tentación a la que deben enfrentarse los autores, agentes, editores y críticos. Es un pecado capital que han cometido muchas veces. Actualmente hay muy pocos lectores como Tucídides y Platón y publicar, por tanto, lo que a ellos les gustaría leer resulta poco lucrativo.

\section{Agelastia}

En sus ensayos críticos, M. Kundera utiliza una y otra vez el término agélastos (sic), que designa en griego al que no sabe reír. Para Kundera, la agelastia (sic) es un concepto estético fundamental que remite a Rabelais y a sus seguidores (por ejemplo, L. Sterne en Tristram Sandy). Los agélastoi hubieran quemado los escritos de Rabelais, y lo hubieran quemado a él mismo, más por desacuerdo estético que por fidelidad a un dogma:

[...] el desacuerdo visceral con lo no serio; la indignación contra el escándalo de una risa desplazada. Y es que, si lo agélastoi tienden a ver un sacrilegio en cada broma, es porque, en efecto, cada broma es un sacrilegio. Hay una incompatibilidad infranqueable entre lo cómico y lo sagrado (Kundera, 2003).

El vínculo entre risa y novela quedó fijado para siempre en la definición del género que propuso Fielding: un texto en prosa cómico-épico (Fielding, 2001). Sin embargo, el humor y la ironía novelescos no nacieron con la Modernidad. También en la novela antigua, la sonrisa, la risa y la carcajada ocupaban un lugar preferente en el Satiricón y en El asno de oro, incluso en la sentimental novela griega de aventuras. ¿Quién no ha sonreído leyendo la frustrada iniciación sexual de Dafnis y

\footnotetext{
8 «Los poemas más poderosos son demasiado difíciles cognitiva e imaginativamente para ser leídos a fondo por más de unos pocos» (Bloom, 2001: $\mathrm{xxx}$ ).
} 
Cloe (3.13), que acaba con Dafnis llorando a lágrima viva porque es incapaz de imitar a los machos cabríos de su rebaño?

Petronio, Longo y Cervantes deberían ser objeto de imitación. Provocar la risa en el lector es una meta difícil. La ineptitud para alcanzarla se disfraza frecuentemente de seriedad ideológica o sentimental, pero ese tipo de sermones arruina el relato. Por favor, novelistas, aunque hayáis nacido en Úbeda, hacednos reír, o al menos, arrancadnos una sonrisa.

\section{Atropía}

Aceptemos el neologismo 'atropía' para designar la pobreza de tropos. Los tropos (metáfora, metonimia, pero también hipálage, etc.) no son adornos de la lírica tradicional. El lenguaje metafórico es una poderosa herramienta cognitiva y la piedra angular de toda la literatura, incluida la novela moderna. No hay, ni ha habido, ni habrá buena literatura sin metáforas nuevas, felices, iluminadoras. Cuando el novelista cae en la atropía (la rigidez del lenguaje por ausencia de tropos), comete un pecado mortal. Despreciar la metáfora por pura ideología literaria, rechazarla como si fuera un manido recurso retórico empobrece cognitivamente el relato hasta la miseria. Pero también puede ocurrir que la atropía sea una enfermedad que el novelista padece involuntariamente: su talento es incapaz de crear una metáfora original que funcione.

Si la enfermedad de la atropía tuviera cura (es decir, si la creación de metáforas pudiera enseñarse ${ }^{9}$ ), el tratamiento adecuado se encontraría en las obras de autores como Ismail Kadaré. Veamos el inicio de Abril quebrado:

Cada vez que sentía frío en los pies sacudía ligeramente las rodillas y entonces, bajos su plantas, oía crujir quejumbrosamente los guijarros. En verdad, el lamento venía de su interior. Nunca en su vida había permanecido tanto tiempo inmóvil, al acecho tras un talud al borde del camino grande. La tarde agonizaba. Asustado, aterrado casi, se echó el fusil a la cara para alinear el punto de mira. En breve oscurecería y no podría afina la puntería (Kadaré, 2001: 13).

La traducción es fiel, acertada en las metáforas, inspirada con los recursos onomatopéyicos («crujir quejumbrosamente los guijarros»), pero desgraciadamente termina por descuidar la composición; la única disculpa es que es un traductor el que ha incurrido en la asonancia. Otro ejemplo de Kadaré: en la oscuridad del insomnio, el joven protagonista recuerda la mirada de Diana:

En sus noches (que los intervalos de sueño trataban caóticamente de llenar, como tratan de llenar un oscuro cielo de otoño las estrellas escasas), aquella mirada era lo único que no se enturbiaba en el duermevela. Permanecía ante él, como un brillante extraviado, en cuya creación se hubiera consumido toda la luz del universo (Kadaré, 2001: 157).

Las metáforas de García Márquez también nos deslumbran, sobre todo porque se organizan en sistemas coherentes dentro de cada episodio. Por ejemplo, el sistema metafórico seísmo-volcán-dragón en el episodio de la masacre de Cien años de soledad, que he desarrollado en otra publicación que está

\footnotetext{
${ }^{9}$ Aristóteles niega sin paliativos la posibilidad de enseñar a hacer metáforas; sin embargo, el Pseudo-Longino admite esa posibilidad.
} 
en prensa. También la prometedora Kjersti A. Skomsvold en su primera novela (Cuanto más deprisa voy, más pequeña soy), ofrece muchas metáforas felices. La anciana protagonista, Mathea Martinsen, sale a enterrar furtivamente en el jardín comunitario un cofre con objetos personales que dejen memoria de su existencia después de su muerte: «La brisa es fría y refrescante, aspiro la noche hasta el fondo de mis pulmones e intento tranquilizarme, hace mucho tiempo que no salgo a la calle después del telediario de las nueve» 10 .

\section{Idolatría}

Cuando un novelista interrumpe su relato para describir un lugar, un objeto o un personaje, la parálisis amenaza su obra. Esas pausas pueden ser síntomas de un narrador exhausto. La vida, representada en acciones hasta ese instante, se transforma en una naturaleza muerta. Pero los poetas y prosistas de todas las épocas han caído una y otra vez en la tentación de «pintar» con palabras un rostro humano o un objeto de arte.

Este es un pecado de idolatría (adoración de las imágenes) y de envidia hacia los artistas plásticos. Desde la Grecia Arcaica, el poeta rivalizaba con el escultor. Una institución social fomentaba esa competencia: los premios para los vencedores en las Olimpíadas y demás juegos deportivos además de la conocido corona de laurel - eran un himno compuesto en su honor y una escultura. El poema parecía una obra precaria y efímera al lado de la escultura, que perduraba, a veces hundida en el fondo del mar, durante veinticinco siglos.

Los novelistas, sin embargo, deben luchar en su propio terreno. Como observó agudamente Lessing, la literatura utiliza como medio de representación el lenguaje, que es temporal y sucesivo. Por tanto, los objetos de representación adecuados para la literatura serían las acciones, que por necesidad suceden en el tiempo.

Mi razonamiento es el siguiente: [...] signos yuxtapuestos no pueden expresar más que objetos yuxtapuestos, o partes yuxtapuestas de tales objetos, mientras que signos sucesivos no pueden expresar más que objetos sucesivos, o parte sucesivas de estos objetos. Los objetos yuxtapuestos, o las partes yuxtapuestas de ellos, son lo que nosotros llamamos cuerpos. En consecuencia, los cuerpos, y sus propiedades visibles, constituyen el objeto propio de la pintura. Los objetos sucesivos, o sus partes sucesivas, se llaman, en general, acciones. En consecuencia, las acciones son el objeto propio de la poesía (Lessing, 1990: 106).

Homero no pretendió retratar a Helena: simplemente narró el efecto de su belleza sobre los ancianos de Troya. Tampoco se molestó en describir armas y arneses, sino que nos contó cómo Agamenón se preparaba para el combate. Cuando se refiere al carro de Hera (Juno para los romanos), no presenta la escena en que Hebe lo monta a la vista de todos.

Por ejemplo, cuando Homero quiere mostrarnos el carro de Juno, es necesario que Hebe lo componga ante nuestros ojos, pieza por pieza. Vemos las ruedas, los ejes, el asiento, la lanza del carro, las correas y las cuerdas no tanto en el conjunto que naturalmente forman cuanto del modo y la manera como van formando una unidad bajo las manos de Hebe (Lessing, 1990: 108).

\footnotetext{
${ }^{10}$ Ofrezco una traducción personal del pasaje en la versión inglesa, que es preferible a la versión española (Skomsvold, 2009: 46).
} 


\section{Cobardía}

Algunos novelistas cobardes se atrincheran al abrigo de las convenciones narrativas de antes de la guerra de Cuba, contra las que clamaba Vila-Matas en el inculto agosto de 2010, sorprendido de que los partidarios de recomendar lecturas estivales hubiesen elegido Verano de Coetzee. Aquel estéril año de 2010, el Premio Nacional de Narrativa recaería en un obra historiográfica.

A otros novelistas el miedo a sentirse antiguos entre sus contemporáneos los impulsa a correr a la vanguardia. Prefieren una brillante aunque efímera carrera, como fuegos de artificio, aunque eso mismo los condene a un olvido prematuro, como nos advierte también Vila-Matas en Aire de Dylan: «para un verdadero creador estar a la última solo puede plantearle problemas para desarrollar la obra propia en libertad, es decir, sin tener que estar todo el rato tiñéndose el pelo para parecer más joven» (Vila-Matas, 2012: 173).

El camino es arduo y está lleno de peligros. Después de Cien años de soledad, García Márquez se lanzó a un experimento que resultó fallido: El otoño del patriarca. Luego, se refugió en los cuarteles de invierno de la novela del siglo XIX y escribió El amor en los tiempos del cólera.

\section{Apatía}

Para no cometer el último de los pecados capitales, la falta de pasión, el novelista debe tener siempre presente el libro II de la Retórica de Aristóteles. Las pasiones mueven el alma, y son también el motor de todos las obras dramáticas y narrativas que nos interesan. La ira, la calma, el amor, el odio, el miedo y el valor, la vergüenza, el agradecimiento, la compasión, la indignación, la envidia o el deseo de emulación turban a veces nuestros corazones, pero siempre el de los personajes que se apoderan de nuestra fantasía. En el catálogo aristotélico de las pasiones, falta la culpa, pero de un griego no debemos esperar que golpee su frente contra un muro de arrepentimiento.

La vida languidece sin pasiones. Con frecuencia sufrimos el tedio de la rutina. Por eso el novelista puede sentir la tentación de crear un mundo ficcional paralelo sin sustancia y aburrido, donde no pasa nada o casi nada, donde el narrador y los demás personajes parecen anestesiados, y una sordina invisible atempera las palabras, hasta llegar a convertirse en «el colmo del aburrimiento», como escribió Auden en el ambiguo elogio de su poema «El novelista»:

Revestido en su talento como un uniforme, el rango de cada poeta es bien conocido. Pueden sorprendernos como una tormenta, o morir tan jóvenes, o vivir en soledad durante años.

Pueden cargar como un húsares. Pero él debe despojarse de su don adolescente y aprender a ser simple y torpe, como si fuera alguien en el que nadie querría convertirse,

pues para cumplir su más alto propósito, debe llegar a ser el colmo del aburrimiento; someterse a vulgares dolencias, como el amor. Entre los Justos, 
ser justo; entre los Sucios, sucio también;

y en su débil persona, si puede,

cargar tediosamente con todos los males del Hombre (Auden, 2007: 123).

Pero el lector de narraciones no quiere que lo aburran. Es más, está ávido de oír un cuento que lo conmueva y quiere encontrarse — quizá solo en el mundo de la ficción — con el colérico Aquiles, el astuto y resiliente Odiseo, el orgulloso Dante (personaje de la Divina Comedia), el colérico, liberal, compasivo y melancólico Don Quijote, Yago el envidioso, la rebelde Emma, el pacífico Don Perlimplín, los amantes Baltasar Sietesoles y Blimunda Sietelunas.

\section{Siete virtudes}

A modo de coda, me gustaría ejemplificar las virtudes contrarias a esos pecados capitales con la más reciente novela de Julian Barnes, Niveles de vida, pero también sería posible hacerlo con la que probablemente será la última de Milan Kundera, La fiesta de la insignificancia. En una crítica precisa y profunda, Darío Villanueva calificaba Niveles de vida como «una pequeña — solo por su extensiónobra maestra, [...] un texto de insólita profundidad para los tiempos que corren» (Villanueva, 2014: 18). También decía en esa misma reseña: «la hondura del sentimiento, y de la reflexión sobre él, hacen de esta breve narración un texto trascendente» (Villanueva, 2014: 18).

Hay que decir que la novela trata del duelo del narrador por la pérdida de su esposa. Julian Barnes es un escritor británico devoto de Flaubert, y su estilo se caracteriza por unas metáforas irreprochables. No debe extrañarnos, pues, esta combinación de profundidad de pensamiento y fuerza metafórica. Tampoco debe extrañarnos que ese conmovedor tratamiento del duelo señalado por Darío Villanueva sea compatible con la sonrisa, incluso con la risa entre lágrimas.

Nació [Nadar, uno de los pioneros de los vuelos en globo] en 1820 y murió en 1910. Era un hombre alto y desgarbado, con una melena pelirroja y de natural apasionado e inquieto. Baudelaire dijo de él que era «una asombrosa expresión de vitalidad»; sus arranques de energía y su pelo llameante parecían capaces de elevar el globo por sí solos. Nadie lo acusó nunca de ser sensato (Barnes, 2014: 25).

Me propusieron otras distracciones, me dieron otros consejos. Algunos reaccionaron como si la muerte del ser querido fuese únicamente una forma extrema de divorcio. Me aconsejaron que me comprase un perro. Yo respondí sarcásticamente que no me parecía un buen sustituto de una esposa (Barnes, 2014: 94).

Miro mi llavero (que era el de ella): sólo tiene dos llaves, una para la puerta de casa y otra para la entrada trasera del cementerio. Esto es mi vida, pienso. Advierto continuidades extrañas: yo solía frotarle aceite en la espalda porque su piel se secaba fácilmente; ahora froto con aceite el roble reseco del letrero que indica dónde está su tumba (Barnes, 2014: 104).

Hacia el final del Año Cuatro [del duelo], una noche volvía en taxi a casa, poco después de las once. Siempre la añoro en ocasiones así: ya no había un amigable recuento del día, no había una somnolienta presencia silenciosa, ni su mano en la mía. Cuando ya estábamos cerca de mi casa, el taxista empezó a hablar. Un diálogo agradable y trivial hasta la pregunta jocosa: «¿Qué? Su mujer, ya dormida, ¿no?» Tras un silencio atragantado, le respondí lo único que se me ocurrió: «Eso espero» (Barnes, 2014: 128).

Esta es la literatura que mantiene vivos el poder cognitivo, el humor y la ironía, el dominio del lenguaje metafórico, el sentido de la trama, el valor y la pasión. En suma, todo lo que deberían aprender 
los escritores del tercer milenio para no ceder a la tentación y cometer los pecados capitales contra el arte de la novela.

\section{Bibliografía}

Alonso, A. (1986): Materia y forma en poesía. Madrid, Gredos.

Auden, W. H. (2007): Los señores del límite. Traducción, selección y prólogo de J. Doce. Barcelona, Galaxia Gutenberg-Círculo de lectores.

BARNES, J. (2014): Niveles de vida. Traducción de J. Zulaika. Barcelona, Anagrama.

BELlow, S. (2006): Ravelstein. Barcelona, Debolsillo.

BLOOM, H. (2001): El canon occidental. Barcelona, Anagrama.

Borges, J. L. (2011): Cuentos completos. Barcelona, Lumen.

FIElding, H. (2001): «The Comic Epic in Prose. Preface to Joseph Andrews», Famous Prefaces. The

Harvard Classics 39. Puede consultarse el texto citado en http://www.bartleby.com/39/26.html (última consulta, 23/6/2017).

GARCía GuAL, C. (2008): Las primeras novelas. Desde las griegas y latinas hasta la Edad Media. Madrid, Gredos.

GARCía LóPEZ, J. ed. (1996): Pseudo-Longino, Sobre lo sublime. Traducción de José García López. Madrid, Gredos.

KADARÉ, I. (2001): Abril quebrado. Traducción de Ramón Sánchez Lizarralde. Madrid, Alianza.

KUNDERA, M. (2003): «El teatro de la memoria», Le monde diplomatique (edición española), en http://monde-diplomatique.es/2003/05/kundera.html (última consulta, 23/6/2017).

- (2007): El arte de la novela. Barcelona, Tusquets.

- (2014): La fiesta de la insignificancia. Traducción de B. de Moura. Barcelona, Tusquets.

LAGO, E. (2006): Llámame Brooklyn. Barcelona, Destino.

LEssing, G. E. (1909): Laocoonte. Traducción de E. Barjau, Madrid, Tecnos.

Macía, L. ed. (1989): Tucídides, Historia de la guerra del Peloponeso. Traducción de Luis Macía. Madrid, Akal.

MÁRquez, M. Á. ed. (2001): Dionisio de Halicarnaso, Sobre la composición literaria. Traducción de Miguel Ángel Márquez. Madrid, Gredos.

(2013): Berlín/Sevilla. Punto de fuga. Sevilla, Renacimiento (Espuela de Plata).

MENÉNDEZ PElAyo, M. (2008): Orígenes de la novela I-II. Madrid, Gredos.

SKomsvold, K. A. (2009): Cuanto más deprisa voy, más pequeña soy. Madrid, Lengua de trapo.

VALle-InClán, Ramón del (2007): Sonatas. Memorias del Marqués de Bradomín. Madrid, Espasa.

Vila-Matas, E. (2012): Aire de Dylan. Barcelona, Seix Barral.

VillanueVA, D. (2014): «Niveles de vida», El Cultural 17 de octubre de 2014, p. 18. 